\section{Ulmer Heft I}

Im Juni 1998 wurde in Ulm die Klinik für Psychiatrie des Universitätsklinikums neu eröffnet. Seit 20 Jahren stehen wir mit drei Stationen, einer Tagesklinik, mehreren Ambulanzen und einem Psychotherapieinstitut für Patienten zur Verfügung. Daneben gehören die Lehre in der medizinischen Fakultät (und neuerdings auch im Institut für Psychologie der Universität Ulm), und natürlich neurowissenschaftliche Forschung zu unserem Profil. In einem Festakt am 5. Juni 2018 wurde unser Jubiläum vom Oberbürgermeister der Stadt Ulm, Vertretern des Klinikums und der Universität Ulm sowie dem Sozialminister des Landes Baden-Württemberg gewürdigt. Das vorliegende sowie das kommende „Ulmer Heft" der Nervenheilkunde runden mit Artikeln zu aktuellen Forschungsthemen die Feierlichkeiten zum 20-jährigen Jubiläum ab.

Schmerzen können sowohl durch körperliche Beschwerden als auch durch seelische Vorgänge ausgelöst werden. Insbesondere soziale Zurückweisung löst regelhaft Schmerzempfinden aus. In einer Übersicht stellen Kathrin Malejko und Koautoren die Neurobiologie des sozialen Schmerzes vor und beleuchten die Rolle des Schmerzsystems bei psychischen Störungsbildern.

Verena Rau und Kollegen beschäftigen sich mit einem verwandten neurowissenschaftlichen Thema: dem Belohnungssystem. Sie zeigen einen wenig bekannten $\mathrm{Zu}$ sammenhang zwischen Opioiden, die (auch) den Schmerz dämpfen können, und Dopamin, dem „eigentlichen“ Transmitter des Belohnungssystems. Es gibt klare tierexperimentelle Befunde, die zeigen, wie Opioide das dopaminerge System modulieren. Dies hat natürlich besonders im Bereich der Suchttherapie klinische Relevanz.

Der Beitrag von Simon Sanwald und Koautoren beschäftigt sich mit Genetik und Epigenetik bei dem Krankheitsbild Depression. Anders als bei Erkrankungen, die auf die Funktion eines einzigen Genes zurückzuführen sind, haben bei den meisten psychischen Erkrankungen wie beispielsweise der Depression oder Schizophrenie eine Vielzahl von Genen einen Einfluss auf die Disposition zur Krankheit.
Ein neuerer Ansatz beschäftigt sich mit Epigenetik, also der Regulation der Aktivität von Genen. Unter bestimmten Annahmen kann hierdurch plausibel werden, wie Umwelteinflüsse, z. B. Stress oder Trauma, die Expression verschiedener Gene verändern und somit Einfluss auf psychisches Erleben und Verarbeiten nehmen können.

René Zeiss und Koautoren beschäftigen sich mit einem pharmakologischen Thema. Die Hemmung der Serotoninwiederaufnahme der gleichnamigen modernen Antidepressiva betrifft nicht nur Nervenzellen, sondern auch Thrombozyten, und verändert damit die Dynamik der Gerinnung. Daraus resultiert ein spezifisches Blutungsrisiko durch SSRI, welches bei der Medikation beachtet werden muss.

In einem Fallbericht schildern Mohammed Elsayed und Koautoren eine klassische psychosomatische Konstellation, die Takotsubo-Kardiomyopathie. Hinter diesem Eponym verbirgt sich eine akute Bewegungsstörung der linken Herzwand, die infarktähnliche Symptome erzeugt und oft von akuten psychisch belastenden Ereignissen ausgelöst wird.

Zwei Beiträge beschäftigen sich mit einer großen Therapie-Innovation, die kürzlich zur Behandlung zugelassenen Antisense-Oligonukleotide. Die hochspezifische Bindung an eine Boten-RNA kann die Proteinexpression hemmen und damit die genetische Ursache einer Erkrankung gezielt angreifen. Claudia Wurster und Koautoren stellen die zugelassenen Medikamente zur Behandlung der Muskeldystrophie und spinalen Muskelatrophie vor und gehen auf weitere neurologische Indikationen ein, bei denen bereits klinische Prüfungen initiiert sind. Heiko Graf und Koautoren diskutieren den potenziellen Einsatz dieses Therapieverfahrens bei weiteren neurologischen und psychischen Erkrankungen. Sie zeigen die Grenzen dieses Verfahrens auf und beleuchten die Problematik der exorbitanten Kosten, die die bisherigen Finanzierungsmodelle der Gesundheitssysteme nicht bewältigen können.

Thomas Kammer \& Manfred Spitzer, UIm

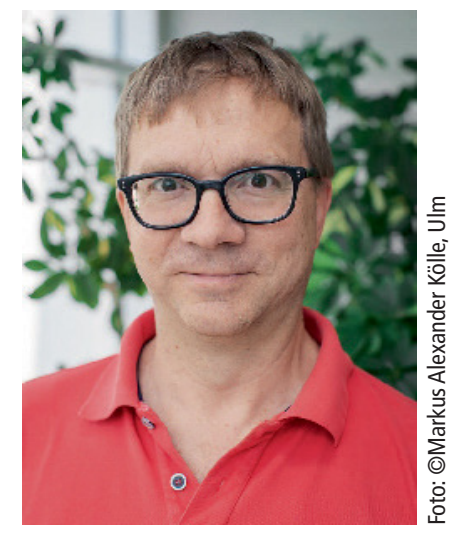

Prof. Dr. Thomas Kammer, Sektion für Neurostimulation, Klinik für Psychiatrie und Psychotherapie III, Universität Ulm

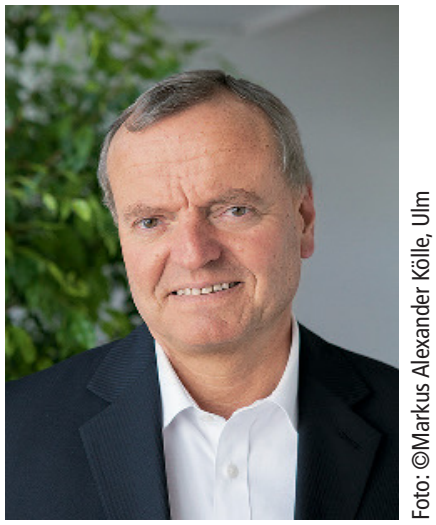

Prof. Dr. Dr. Manfred Spitzer, Klinik für Psychiatrie und Psychotherapie III, Universität Ulm 